\title{
Development of a method for the
} determination of SCCPs (short-chain chlorinated paraffins) in bivalve mollusk using Soxtec device followed by gas chromatography-triple quadrupole tandem mass spectrometry

\author{
N. Carro*, J. Cobas, I. García, M. Ignacio, A. Mouteira and B. Silva
}

\begin{abstract}
Background: Organochlorinated compounds are major environmental concern due to their persistence, long-range transportability and bio-accumulation. Chlorinated paraffin (CP) mixtures, especially short-chain CPs (SCCPs), are found in environmental samples at very high levels. However, information about their levels is still insufficient, mainly in marine biota.

Methods: This study aimed to optimize and validate a method for the determination of SCCPs (short-chain chlorinated paraffins) in bivalve mollusk using a Soxtec extractor and Gas Chromatography coupled with Mass Spectrometry in tandem GC-QqQ-MS/MS (EI). A Plackett-Burman $\left(2 \wedge 7^{*} 3 / 16\right)$ type III resolution factorial design was used to optimize the extraction and purification procedures, sample amount, extractant volume, boiling and rinsing times as extraction variables and alumina, acid silica gel amounts and elution volume as purification variables.

Results: The most influent factors were sample amount, rinsing time, extractant volume and acid silica gel amount. Further experiments were performed in order to attain the optimal values of these factors $(4 \mathrm{~g}$ sample amount, $50 \mathrm{~mL}$ $\mathrm{n}$-hexane-dichloromethane as extractant volume, 2 and $1.5 \mathrm{~h}$ boiling and rinsing times, $8 \mathrm{~g}$ alumina, $4 \mathrm{~g}$ acid silica gel (15\%) and $50 \mathrm{~mL} \mathrm{n}$-hexane-dichloromethane as elution solvent). Validation of the optimized method presented recoveries higher than 90\% with RSD below 10\%, showing good accuracy and precision. The whole method limits of detection and quantification were $46.13 \mathrm{mg} \mathrm{Kg}^{-1}$ and $153.75 \mathrm{mg} \mathrm{Kg}^{-1}$, respectively. This method was successfully applied to the analysis of wild mussel samples coming from two Galician Rías. The found levels were very low compared to other marine systems, below parts per million.
\end{abstract}

Conclusions: The main advantages of the optimized method lie in the rapidity and the low amount of sorbents and volume of solvent used, as well as the selectivity and sensitivity of triple quadrupole MS/MS.

Keywords: SCCPs, Bivalve mollusk, Soxtec, GC-QqQ-MS/MS

\footnotetext{
*Correspondence: ncarro@intecmar.gal

Instituto Tecnolóxico para o Control do Medio Mariño de Galicia, INTECMAR,

Consellería do Mar, Xunta de Galicia, Peirao de Vilaxoán s/n, 36611 Vilagarcía

de Arousa, Spain
} 


\section{Background}

Short-chain chlorinated paraffins (SCCPs) are complex technical mixtures of halogenated contaminants with linear carbon chain lengths from 10 to 13 . The chlorine content ranges from 30 to $70 \%$ (calculated by weight). Technical mixtures are used as extreme pressure additives in lubricants, flame retardants in plastics and paints, plasticizers in coatings, sealants and adhesives, and in leather fat liquors. They have replaced the PCBs uses in industrial mixtures (De Boer et al. 2010). SCCPs are of great interest due to their persistence, toxicological properties, and high octanol-water partition coefficient $\left(K_{\text {ow }}\right)$ that make them tend to bioaccumulate in lipid tissues of marine organisms and can be transferred and magnified along the food chain (Feo et al. 2009; Yuan et al. 2012). Besides, SCCPs have been found in remote areas. In consequence, it is possible to think about their long-range atmospheric transport (Tomy et al. 2000). Chlorinated paraffins (CPs) have similar properties to other persistent organic pollutants (POPs) and already subject to assessment by Stockholm Convention (UNEP/ POPS/POPRC.11/4 2015). The western countries have begun to restrict the usage and production of CPs (van Mourik et al. 2016).

The quantification of CPs, like POPs, includes the extraction, purification, fractionation, and chromatographic determination. Soxhlet device is a conventional liquidsolid extraction technique that uses high solvent volumes and extraction times in the range 6-24 $\mathrm{h}$; it has been extensively used in CPs applications (Parera et al. 2004; Basconcillo et al. 2015). More recent extraction techniques, such as accelerated solvent extraction (ASE), ultrasonic-assisted extraction (USE), microwaveassisted extraction (MAE), and supercritical fluid extraction (SFE), use reduced solvent volumes in shorter time and allow high levels of automation. These techniques have also employed in the CPs extraction by several authors (Tomy and Stern 1999; Parera et al. 2004; Ma et al. 2014). In 1982, Foss commercialized the Soxtec device with the aim of reducing the Soxhlet parameters (Randall 1974). The main difference with the conventional Soxhlet is the incorporation of a previous step in which the sample is completely submerged in the extraction solvent in order to facilitate the rapid solubilization of analyte in boiling solvent (the boiling step); it allows a more efficient extraction and reduces the extraction time and solvent volume. Soxtec devices consist of three more steps. In the rinsing step, the sample thimble is hung above the surface of the solvent; the sample is rinsing by condensed solvent. In the recovery step, the distilled solvent is automatically collected. In the pre-drying step, there is an elimination of boil dry maintaining the temperature of the hot plate.
In relation to purification and fractionation steps, they would have to be very specific given that large amounts of compounds are co-extracted with CPs. In biota analysis, besides the separation of CPs from interfering organochlorine compounds, the lipid elimination is necessary. The multi-layer columns with different combinations of inorganic adsorbents (neutral, acid, and basic silica; Florisil; alumina) are the most used (Borgen et al. 2003; Parera et al. 2004; Reth et al. 2005; Marvin et al. 2003). GPC (gel permeation chromatography) is another widespread purification technique (Coelhan et al. 2000). Some authors use the photolytic cleanup of biota samples, and interfering compounds are destroyed immediately (Friden et al. 2004).

Although gas chromatography (GC) is the most widely used technique, it is impossible to separate $\mathrm{CP}$ mixtures into single compounds, so the use of GCxGC should be more appropriate (Korytar et al. 2005). The GC coupled to ECD (electronic capture detector) has also been used in CPs determination, but this detector is little selective in organochorine-rich extracts. However, the GC coupled to mass spectrometry with electron capture negative ionization (GC-ECNI-MS) is today the more frequently used approach (Tomy et al. 1997; Reth and Oehme 2004; Gandolfi et al. 2015). Nowadays, the GC coupled to triple quadrupole mass spectrometry in mode Mass/Mass (GC-QqQ-MS/MS) is beginning to be used for analysis of CCPs in environmental samples using fragments of low $\mathrm{m} / \mathrm{z}$ (Zencak et al. 2005; Tölgyessy et al. 2017). The further fragmentations carried out by tandem mass spectrometry GC-QqQMS/MS open a world of possibilities to achieve good selectivity and sensitivity, in relation to low-resolution devices. The strong fragmentation of paraffins under EI conditions gives weak compound-specific information (number of chlorine atoms and chain length); however, this disadvantage can be useful for total SCCPs analysis because some fragments are present in all or most CPs mass spectra, and then, the response factors of different $\mathrm{CP}$ mixtures are independent from their degree of chlorinations.

Several studies have shown the extensive presence of SCCPs in several marine compartments (Reth et al. 2006; Zeng et al. 2012). However, there is little information regarding SCCPs concentration in mollusk limited to bivalves from coastal waters in the Chinese Bohai Sea (Yuan et al. 2012; Ma et al. 2014). Most of the developed method have been tested and applied for the determination of CPs in marine sediments and fish samples (Beaume et al. 2006; Coelhan et al. 2000; Reth et al. 2005; Castells et al. 2008; Zeng et al. 2012; Zeng et al. 2013; Ma et al. 2014; Basconcillo et al. 2015).

The aim of this work was to optimize a simple method for the determination of SCCPs in samples of bivalve 
mollusk. The extraction of analytes is performed by using a Soxtec device and its purification by means of multilayer columns. Because of the high number of variables that potentially affect paraffins determination, a Plackett-Burman $2^{7}$ factorial design (Minitab 16 statistical package), which consists of seven factors with two levels for each factor, has been applied on a freeze-dried mussel spiked with a mixture of SCCPs. Seven experimental variables of extraction and purification have been optimized (sample amount, extractant volume, boiling and rinsing times, alumina amount, acid silica gel amount, and elution volume). Extracts have been analyzed by gas chromatography coupled to tandem mass spectrometry GC-QqQ-MS/MS (EI). The optimized and validated method has been applied to real samples from Galician Rías.

\section{Methods}

\section{Material and apparatus}

$N$-hexane for pesticide residue analysis was supplied by Carlo Erba (Milan, Italy). Dichloromethane for organic residue analysis was purchased from J.T. Baker (New Jersey, USA). Aluminum oxide, anhydrous sodium sulphate, and silica gel were supplied by Merck (Darmstadt, Germany). Sulfuric acid (purify 95\%) was acquired by Panreac (Barcelona, Spain). Alumina and silica gel were dried at $800{ }^{\circ} \mathrm{C}$ for $4 \mathrm{~h}$ and $210{ }^{\circ} \mathrm{C}$ for $24 \mathrm{~h}$, respectively. Alumina was hydrated at $6 \%$, and silica gel acidified at 15 or $30 \%$ according to experiments. Reference SCCPs technical mixture with chlorine content of $55.5 \%$ (100 $\mathrm{ng} / \mu \mathrm{L}$ in cyclohexane) was purchased by Dr. Ehrenstorfer GmbH (Augsburg, Germany). The internal standard, $\varepsilon-\mathrm{HCH}(10 \mathrm{ng} / \mu \mathrm{L}$ in cyclohexane), was also obtained from Dr. Ehrenstorfer GmbH. SCCPs mixture was used to fortify the samples of freeze-dried mussel used during the optimization of the sample preparation conditions. Further dilutions were prepared in n-hexane to optimize GC-MS determination conditions (calibration standards).

Extractions were performed in an extractor, Soxtec ${ }^{\mathrm{Tm}}$ 2055 System (FOSS Analytical AB, Höganäs, Sweden), with a refrigerator (Julabo F250). The cellulose thimbles were provided by FOSS (diameter $33 \mathrm{~mm}$, length $80 \mathrm{~mm}$ ).

Extract concentration was carried out by using heating and evaporating units, Reacti-Therm supplied by Pierce (Rockford, USA).

SCCPs were determined using a GC-MS/MS system consisting of an Agilent 7890B gas chromatograph equipped with a split/splitless injector (Agilent 7693 Autosampler) and connected to a triple quadrupole type mass spectrometer (Agilent MS 7000D). The separations were carried out by using an Optima 5 MS (MacheryNagel, German) 5\% diphenyldimethyl siloxane capillary column $(50 \mathrm{~m} \times 0.20 \mathrm{~mm}$ i.d. $\times 0.35 \mu \mathrm{m}$ phase thickness $)$.

\section{Samples and sample procedure}

The optimization of the sample preparation conditions was carried out on a freeze-dried pooled of mussel matrix (Mytilus galloprovincialis) from raft polygons in the Galician coast (northwest of Spain). The spiking procedure consisted of the addition of a given volume of standard in an accurately weighed sample fraction. The resulting slurry was homogenized periodically and kept in a hood until complete elimination of solvent. All spiked samples $(5 \mathrm{mg} / \mathrm{kg})$ were aged for a week before extraction.

Under working conditions, cellulose thimbles were filled with $4 \mathrm{~g}$ anhydrous sodium sulphate and $2-5 \mathrm{~g}$ spiked sample, according to the experimental conditions. The thimble holder was used to support the thimbles and to attach them to the magnets of the extraction unit. Analytes were extracted with $30-80 \mathrm{~mL}$ $\mathrm{n}$-hexane:dichloromethane (1:1) after $1-2 \mathrm{~h}$ boiling time and $0.5-1.5 \mathrm{~h}$ rinsing time, according to the values dictated by the factorial design or by further experiments. Soxtec extracts were evaporated, ca. $1 \mathrm{~mL}$, and additionally purified with a multilayered column previously conditioned with $\mathrm{n}$-hexane $(50 \mathrm{~mL})$. The multilayer column (glass column, $2 \mathrm{~cm}$ inner diameter and $45 \mathrm{~cm}$ long) was packed from bottom to top with glass wool, 4-8 g hydrated basic alumina (6\%), 2 g activated silica gel, 4-8 g acid silica gel, and $4 \mathrm{~g}$ anhydrous sodium sulphate. After loading the concentrated extract, the sorbent was rinsed with $80 \mathrm{~mL} \mathrm{n}$-hexane and the target analytes were further recovered with $50-130 \mathrm{~mL}$ $\mathrm{n}$-hexane:dichloromethane $(1: 1)$. Elution of sample was carried out at a rate of about $1 \mathrm{~mL} / \mathrm{min}$.

The n-hexane:dichloromethane extract was concentrated to dryness, using firstly a rotary evaporator and then a gentle stream of nitrogen (heating and evaporating units). Finally, the residue was re-dissolved with $0.2 \mathrm{~mL}$ of $\mathrm{n}$-hexane. Internal standard $(5 \mu \mathrm{L})$ was added to each sample as injection standard. A $2 \mu \mathrm{L}$ volume was injected into the GC-MS/MS system.

The proposed method was applied to several Galician mussel (Mytilus galloprovincialis) samples.

\section{Instrumental analysis}

Experimental conditions in the GC-MS/MS triple quadrupole system were an aliquot of $2 \mu \mathrm{L}$ of the final extract was injected using the splitless mode (splitless time, $0.75 \mathrm{~min}$ ). The injector temperature was set at $280{ }^{\circ} \mathrm{C}$. Helium was used as carrier gas at a constant flow rate of $1.0 \mathrm{~mL} / \mathrm{min}$. The temperature program was as follows: $1 \mathrm{~min}$ isothermal program at $50{ }^{\circ} \mathrm{C}$, increased to $320^{\circ} \mathrm{C}$ at $30{ }^{\circ} \mathrm{C} / \mathrm{min}$ and held for $15 \mathrm{~min}$. The transfer line temperature was set at $280{ }^{\circ} \mathrm{C}$, the ion source and Q1 and Q3 temperatures at 280,180 , and $180{ }^{\circ} \mathrm{C}$, respectively. The electron energy was set at $70 \mathrm{eV}$, the emission 
Table 1 Experimental parameters of extraction and purification steps, factor levels tested in the factorial design, and optimum values for SCCP determination

\begin{tabular}{|c|c|c|c|c|}
\hline Factor & Low level & High level & Center & Optimum \\
\hline Sample amount (g) & 2 & 4 & 3 & 4 \\
\hline Extractant volume (mL) & 30 & 50 & 40 & 50 \\
\hline Boiling time (h) & 1 & 2 & 1.5 & 2 \\
\hline Rinsing time (h) & 0.5 & 1 & 0.75 & 1.5 \\
\hline Alumina amount (g) & 4 & 8 & 6 & 8 \\
\hline Acid silica amount (g) & $4\left(30 \% \mathrm{H}_{2} \mathrm{SO}_{4}\right)$ & $8\left(30 \% \mathrm{H}_{2} \mathrm{SO}_{4}\right)$ & $6\left(30 \% \mathrm{H}_{2} \mathrm{SO}_{4}\right)$ & $4\left(15 \% \mathrm{H}_{2} \mathrm{SO}_{4}\right)$ \\
\hline Elution volume (mL) & 80 & 130 & 105 & 50 \\
\hline
\end{tabular}

current at $35 \mu \mathrm{A}$, and dwell time at $75 \mathrm{~ms}$. Nitrogen was used as CID gas. SCCPs were detected using the $\mathrm{m} / z$ 103 to 65 , the $m / z 102$ to 67 , the $m / z 91$ to 53 , and the $\mathrm{m} / z 89$ to 53 transitions with collision energy of $10 \mathrm{~V}$. The precursor ion $m / z 219$ and the product ion $m / z 109$ were chosen for $\varepsilon-\mathrm{HCH}$ (collision energy of $40 \mathrm{~V}$ ).

\section{Data processing}

Data analysis of the experimental design was performed by means of the statistical package Minitab 16 .

The standardized effect of each factor was calculated using the statistical package. The magnitude of the standardized effect of the tested factor indicates its significance in affecting the response, while the positive and the negative signs are indicative of its positive and negative influence on the responses, respectively.

\section{Results and discussion}

Experimental design

Since the number of variables potentially affecting the efficiency of the extraction and purification is very large (sample amount, extractant volume, and boiling and rinsing times as extraction variables and alumina amount, acid silica gel amount, and elution volume as purification variables), a screening factorial design Plackett-Burman $\left(2^{\wedge} 7^{*} 3 / 16\right)$ type III resolution at two levels has been applied. If a two-level full factorial design $2^{\wedge} 7$ is applied, 128 experiments need to be carried out, in addition to the replicates needed for statistical evaluation of the coefficients for the fitted model and the degree of coincidence of the hyperplane obtained with the true response surface. Plackett-Burman designs allow to fractionate the full factorial design, giving numbers of factor combinations that are a multiple of

Table 2 Design matrix and response values (area counts) for Plackett-Burman factorial design

\begin{tabular}{|c|c|c|c|c|c|c|c|c|}
\hline & $\begin{array}{l}\text { Sample } \\
\text { amount } \\
\text { (g) }\end{array}$ & $\begin{array}{l}\text { Extractant } \\
\text { volume } \\
(\mathrm{mL})\end{array}$ & $\begin{array}{l}\text { Boiling } \\
\text { time } \\
\text { (h) }\end{array}$ & $\begin{array}{l}\text { Rinsing } \\
\text { time } \\
\text { (h) }\end{array}$ & $\begin{array}{l}\text { Alumina } \\
\text { amount } \\
\text { (g) }\end{array}$ & $\begin{array}{l}\text { Acid silica } \\
\text { amount } \\
\text { (g) }\end{array}$ & $\begin{array}{l}\text { Elution } \\
\text { volume } \\
(\mathrm{mL})\end{array}$ & Area counts \\
\hline EXP 1 & 2 & 30 & 2.0 & 1.00 & 8 & 4 & 130 & $7,571,262$ \\
\hline EXP 2 & 4 & 50 & 1.0 & 1.00 & 8 & 4 & 130 & $10,786,966$ \\
\hline EXP 3 & 4 & 30 & 1.0 & 0.50 & 8 & 8 & 130 & $5,778,221$ \\
\hline EXP 4 & 2 & 30 & 1.0 & 1.00 & 8 & 8 & 80 & $3,682,164$ \\
\hline EXP 5 & 2 & 50 & 1.0 & 0.50 & 4 & 8 & 130 & $3,326,814$ \\
\hline EXP 6 & 4 & 50 & 1.0 & 1.00 & 4 & 4 & 80 & $12,009,019$ \\
\hline EXP 7 & 2 & 30 & 1.0 & 0.50 & 4 & 4 & 80 & $4,926,262$ \\
\hline EXP 8 & 3 & 40 & 1.5 & 0.75 & 6 & 6 & 105 & $1,259,106$ \\
\hline EXP 9 & 4 & 30 & 2.0 & 1.00 & 4 & 8 & 80 & $8,364,945$ \\
\hline EXP 10 & 2 & 50 & 2.0 & 1.00 & 4 & 8 & 130 & $7,771,676$ \\
\hline EXP 11 & 4 & 30 & 2.0 & 0.50 & 4 & 4 & 130 & $6,350,117$ \\
\hline EXP 12 & 4 & 50 & 2.0 & 0.50 & 8 & 8 & 80 & $8,841,669$ \\
\hline EXP 13 & 2 & 50 & 2.0 & 0.50 & 8 & 4 & 80 & $6,700,095$ \\
\hline EXP 14 & 3 & 40 & 1.5 & 0.75 & 6 & 6 & 105 & $1,816,600$ \\
\hline
\end{tabular}




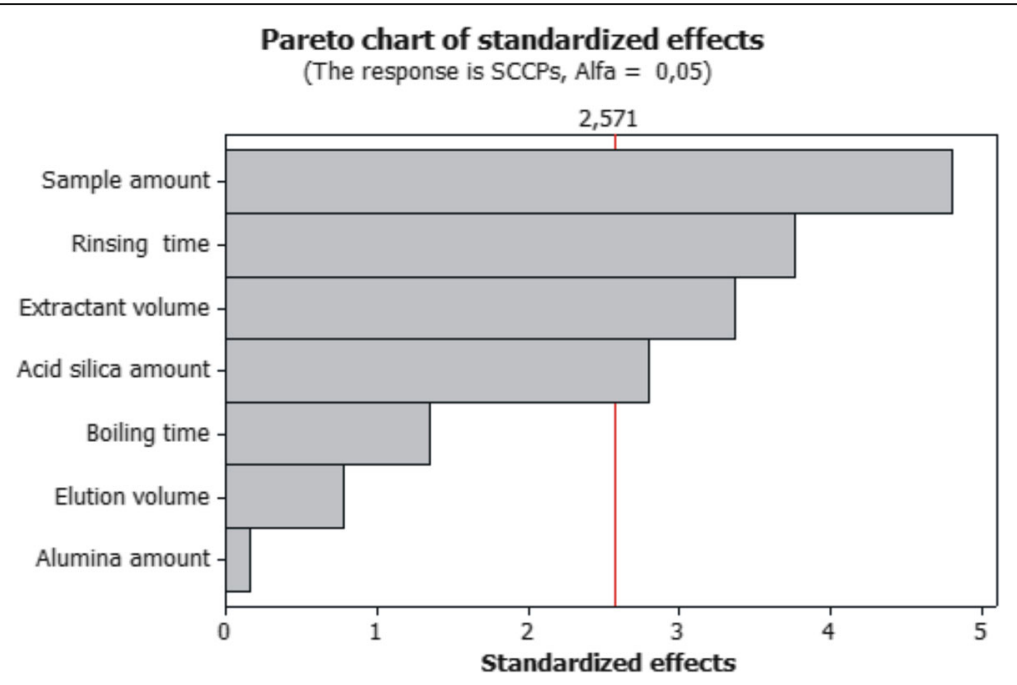

Fig. 1 Pareto charts of main effects for the factorial design. The vertical lines indicate the statistical significance bound for the effects

four. Our particular Plackett-Burman $\left(2^{\wedge} 7^{*} 3 / 16\right)$ type III resolution design with two center points and one replicate involved 14 randomized runs. The type III resolution designs can estimate only the main effects. They are typically used to identify a few significant factors out of a large set.

Table 1 shows the upper and lower levels given to each factor. Such values were selected from experience gathered in previous screening experiments. Table 2 summarizes the design matrix for these experiments and the area counts obtained in each one for total SCCPs.

The numerical analysis of the results in the factorial design leads to Pareto chart of the standardized main effects shown in Fig. 1. The conclusions are that the sample amount, the rinsing time, the extractant volume (extraction variables), and the acid silica gel amount (purification variable) were statistically significant. The other factors had no statistical significance. Table 3 summarizes the value of estimated effects for total SCCPs.

Table 3 Value of estimated effects of experimental parameters for SCCP determination

\begin{tabular}{llll}
\hline Term & Effect & $t$ & $p$ \\
\hline Constant & & 21,97 & 0.000 \\
Sample amount & $3,025,444$ & 4.63 & 0.006 \\
Extractant volume & $2,127,211$ & 3.26 & 0.023 \\
Boiling time & 848,386 & 1.30 & 0.251 \\
Rinsing time & $2,377,142$ & 3.64 & 0.015 \\
Alumina amount & 101,924 & 0.16 & 0.882 \\
Acid silica amount & $-1,763,039$ & -2.70 & 0.043 \\
Elution volume & $-489,850$ & -0.75 & 0.487 \\
Ct Pt & & -7.47 & 0.001 \\
\hline
\end{tabular}

Italics mean statistically signicant factors
The most significant factor was the sample amount followed by the rinsing time and extractant volume; these factors had positive sign. The acid silica gel amount was the least significant factor and had a negative effect. With regard to the factor interactions, more sample amount, higher extractant volume, and longer rinsing time were necessary to achieve the best recoveries (see Fig. 2). If the rinsing time was set at the highest level, the boiling time hardly affected on the recovery of SCCPs. The best recoveries were found at the highest level of the boiling time. In Fig. 3, it can be seen that when a greater alumina amount was used, a higher elution volume was necessary during the purification step. However, with regard to the acid silica gel, the highest recoveries were obtained at the lowest value of this factor regardless of the elution volume and the alumina amount.

\section{Further experiments}

The results of Plackett-Burman factorial design suggested that the high level, $8 \mathrm{~g}$, can be considered as the optimal value of the amount of hydrated basic alumina for the total SCCPs determination. According to this factorial design, new experiments shifted in the direction of higher values of factors, such as sample amount and extractant volume would be desirable. With this aim, four experiments were performed fixing the other factors according to the design results, the boiling and rinsing times at 2 and $1 \mathrm{~h}$ (high levels), acid silica gel amount at $4 \mathrm{~g}$ (low level), elution volume at $80 \mathrm{~mL}$ (high level), and varying the values of sample amount between 4 and $5 \mathrm{~g}$ and extractant volume between 50 and $80 \mathrm{~mL}$. The results of these experiments showed that both 4 and $5 \mathrm{~g}$ of sample amount extracted with $50 \mathrm{ml}$ of solvent volume showed the best recoveries. However, $4 \mathrm{~g}$ of sample amount was selected as optimal value with the aim to 


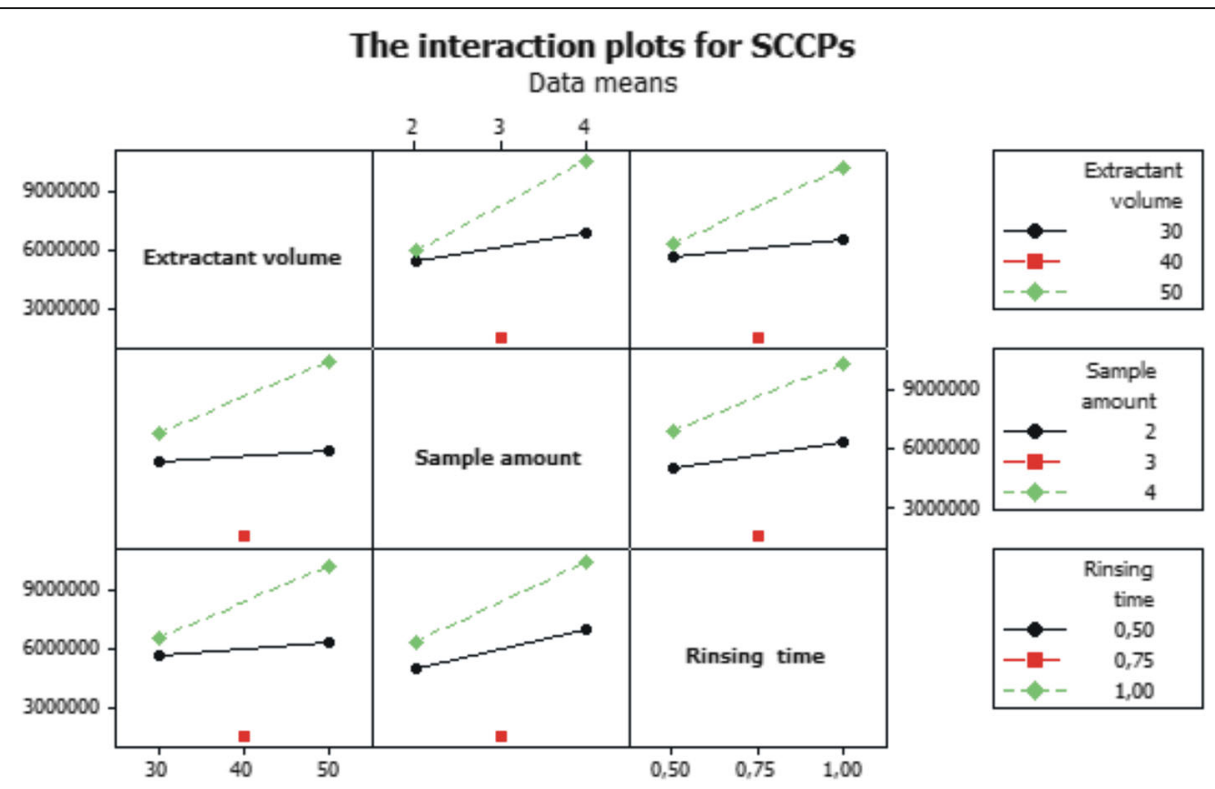

Fig. 2 Interaction plots of the three factors (extractant volume, sample amount, and rinsing time) for SCCP determination

improve the specifications of method. Larger quantities of mollusk caused blockage in purification columns. Another two experiments were carried out fixing the sample amount $(4 \mathrm{~g})$, the extractant volume $(50 \mathrm{~mL})$, and the amounts of other adsorbents at their optimal values and varying the amount of acid silica gel between $4 \mathrm{~g}$ at $15 \%$ sulfuric acid and $2 \mathrm{~g}$ at $30 \%$ sulfuric acid; the two proofs gave very good extraction efficiencies, $91 \%$ respectively. However, when $2 \mathrm{~g}$ acid silica gel at $30 \%$ sulfuric acid was used, the column was plugged hampering the sample elution, so $4 \mathrm{~g}$ silica gel at $15 \%$ sulfuric acid was selected as optimal value. The last experiments of optimization have been performed fixing the variables at their optimal value, $4 \mathrm{~g}$ sample amount, $50 \mathrm{~mL}$ extractant solvent, $8 \mathrm{~g}$ hydrated alumina amount, and $4 \mathrm{~g}$ acid silica gel (15\%) amount, increasing the rinsing time to $1.5 \mathrm{~h}$ (positive significant effect) and varying the boiling time between 1.5 and $2 \mathrm{~h}$ and the elution volume from 80 to $50 \mathrm{~mL}$. The best results

\section{The interaction plots for SCCPs}

Data means

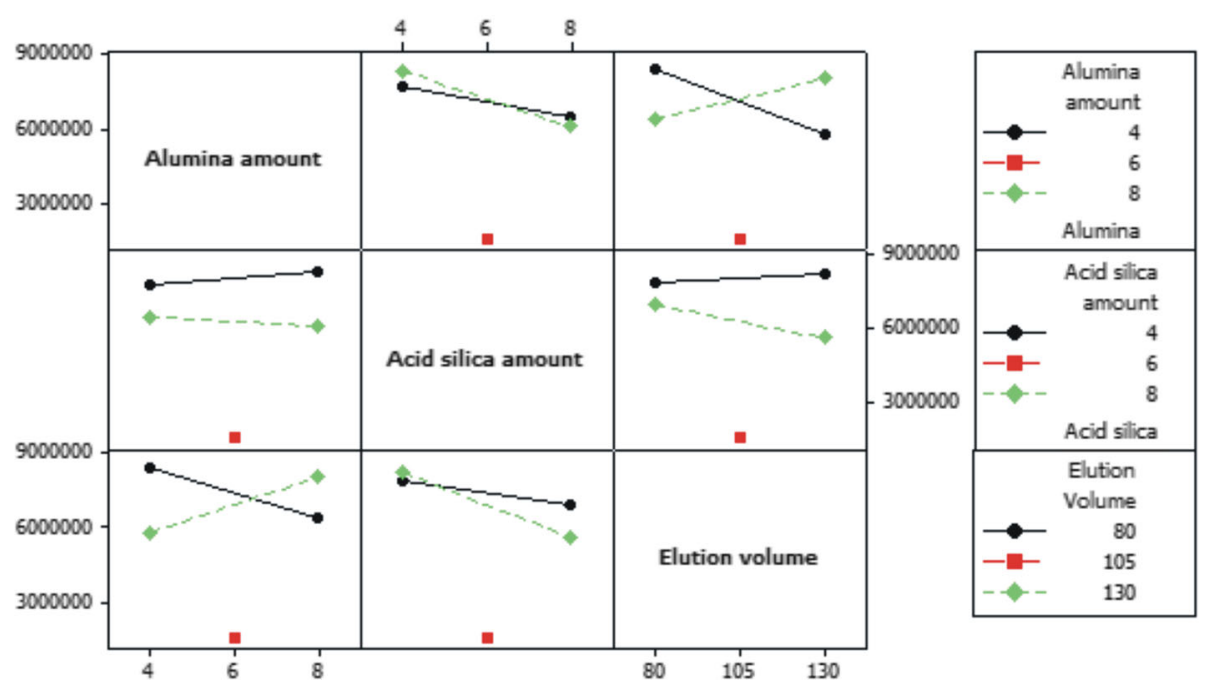

Fig. 3 Interaction plots of the three factors (alumina amount, acid silica amount, and elution volume) for SCCP determination 
were obtained at $2 \mathrm{~h}$ boiling time and $50 \mathrm{~mL}$ elution solvent. In Table 1 , the optimal values of factors for the total SCCPs determination in bivalve mollusk are shown.

\section{Quality control and method performance}

The performance of the optimized method was assessed in terms of linearity, precision (reproducibility), accuracy (recovery), effects of matrix, and limits of detection and quantification.

Signals (peak areas) measured for spiked and nonspiked mussel sample extracts were compared to those obtained for calibration standards in n-hexane, covering the range of concentrations between 10 and $100 \mathrm{ng} / \mathrm{\mu L}^{-1}$. The instrumental linearity was tested at these four levels of concentration. The curves of calibration were obtained injecting each level in duplicate, and the response function was found to be linear with coefficients between 0.998 and 0.999 .

The precision of the method was assessed by calculating the relative standard deviation (RSD) among days ( $n$ $=6$ ); it was lower than $10 \%$.

The recovery of the method was calculated by dividing the difference between the measured concentrations for the spiked samples and non-spiked samples. It was expressed as percentage. The obtained recoveries were satisfactory with values higher than $90 \%$.

The effect of matrix was estimated by comparison of two replicates of an extract of a sample spiked with a

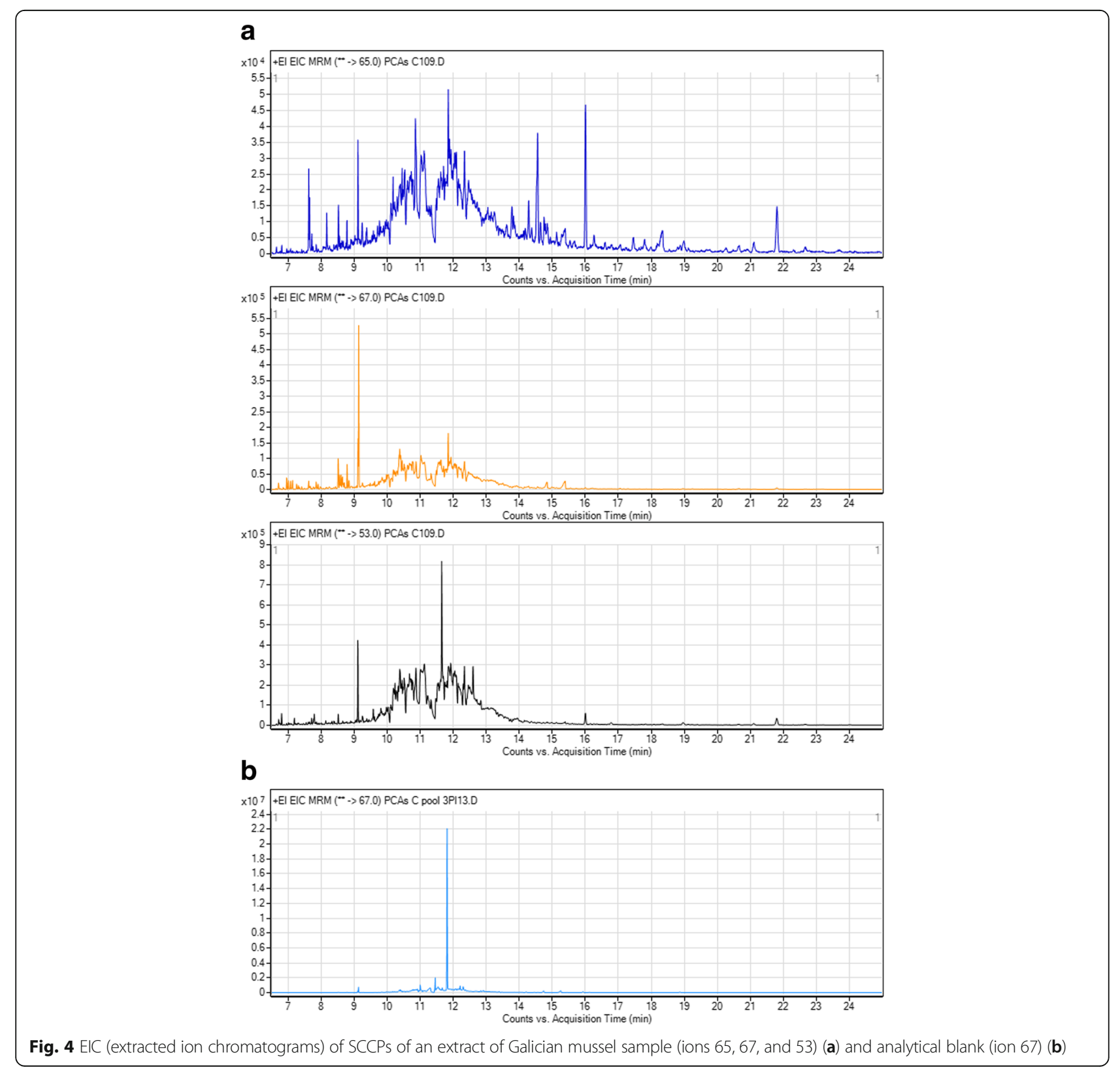


standard at the same concentration level. A value of matrix effect of $100 \%$ would indicate no matrix effect; lower values would indicate signal suppression and higher value signal enhancement. For this method, the value of matrix effect was around 100\% (98\%).

The limits of detection (LODs) and quantification (LOQs) of the overall method were calculated as the concentration giving a signal to noise ratio of three and ten, respectively. For this method, LODs and LOQs were 46.1 and $153.6 \mu \mathrm{g} \mathrm{kg}^{-1}$, respectively.

Potential contamination problems were evaluated with procedural blanks which mimic the whole sample preparation method (extraction plus purification) without sample. At least one blank was processed with each batch of extractions.

\section{Application to real samples}

The optimized and validated method was applied to the analysis of three real samples of wild mussel coming from two estuarine bays in Galicia (NW, Spain), Rías of Ares-Betanzos (Are 1) and Ferrol (Fer 1 and Fer 2). Two extractions were carried out for each sample. Levels of concentration expressed in dry wet were $561.7 \pm 50.7 \mu \mathrm{g} \mathrm{kg}^{-1} \mathrm{~d}$.w. for Are 1, and $524.8 \pm 47.2$ and 919.4 $\pm 82.8 \mu \mathrm{g} \mathrm{kg}^{-1}$ d.w., for Fer 1 and Fer 2, respectively. The two first samples had lower levels than the third sample. This later came from an industrial and populated city in Galicia. The concentration levels found were low compared to the levels of other organisms coming from different marine systems (Coelhan et al. 2000; Ma et al. 2014). In Fig. 4, it can be seen the extracted ion chromatogram (EIC) obtained from three MRM modes (103 to 65 , the $\mathrm{m} / z 102$ to 67 , the $\mathrm{m} / z 91$ to 53) of total SCCPs for an extract of Galician mussel sample and a blank procedure.

\section{Conclusions}

A method for analysis of SCCPs in bivalve mollusk samples by using Soxtec device followed by purification in multilayer column and determination in GC-QqQ-MS/ MS (EI) was optimized and validated. The optimization was performed by using a Plackett-Burman factorial design. The statistically significant variables were sample amount, rinsing time, extractant volume, and acid silica amount. The main advantages of the optimized method lie in the rapidity and the low amount of sorbents and volume of solvent used, as well as the selectivity and sensitivity of triple quadrupole MS/MS. The suitability of the optimized method was demonstrated by the validation, providing a good trueness, recoveries higher than $90 \%$, successful precision, RSD below $10 \%$, and LOQs around $150 \mu \mathrm{g} \mathrm{kg}^{-1}$. The validated method was applied to real samples from the Galician Rías.

\section{Funding}

This work has been financially supported by the Ministry of Economy and Competitiveness, Spain (project no. CTM2014-56628-C3-2-R), and FEDER/ERDF.

Availability of data and materials

The data used in this study is presented in the main paper.

\section{Authors' contributions}

$\mathrm{MI}, \mathrm{AM}$, and BS contributed to the sampling preparation. IG, NC, and JC contributed to the data analysis. NC contributed to the manuscript preparation. All authors read and approved the final manuscript.

\section{Competing interests}

The authors declare that they have no competing interests.

Received: 28 November 2017 Accepted: 22 January 2018

Published online: 06 February 2018

\section{References}

Basconcillo LS, Backus SM, McGoldrick DJ, Zaruk D, Sverko E, Muir DCG. Current status of short and medium chain polychlorinated n-alkanes in top predatory fish across Canada. Chemosphere. 2015;127:93-100.

Beaume F, Coelhan M, Parlar H. Determination of C10-chloroalkane residues in fish matrices by short column gas chromatography/electron capture negative ion low resolution mass spectrometry applying single pure and representative synthesised chlorodecanes as standards. Anal Chim Acta. 2006;565:89-96.

Borgen AR, Schlabach M, Mariussen E. Screening of chlorinated paraffins in Norway. Organohalogen Compd. 2003;60:331-4.

Castells P, Parera J, Santos FJ, Galceran MT. Occurrence of polychlorinated naphthalenes, polychlorinated biphenyls and short-chain chlorinated paraffins in marine sediments from Barcelona (Spain). Chemosphere. 2008;70:1552-62

Coelhan M, Saraci M, Parlar H. A comparative study of polychlorinated alkanes as standards for the determination of $\mathrm{C}_{10}-\mathrm{C}_{13}$ polychlorinated paraffines in fish samples. Chemosphere. 2000;40:685-9.

De Boer J, El-Sayed AT, Fiedler H, Legler J, Muir DC, Nikiforov A, Tomy GT, Tsunemi K. Chlorinated paraffins. In: De Boer J, editor. In the handbook of environmental chemistry, chlorinated paraffins. 10th ed. Berlin: Springer-Verlag; 2010.

Feo ML, Eljarrat E, Barcelo D. Occurrence, fate analysis of polychlorinated n-alkanes in the environment. Rac-Trends Anal Chem. 2009:28:778-91.

Friden $U$, Jansson B, Parlar H. Photolytic clean-up of biological samples for gas chromatographic analysis of chlorinated paraffins. Chemosphere. 2004;54(8):1079-83.

Gandolfi F, Malleret L, Sergent M, Doumeng P. Parameters optimization using experimental design for headspace solid phase micro-extraction analysis of short-chain chlorinated paraffins in waters under the European water framework directive. J Chromatography A. 2015;1406:59-67.

Korytar P, Parera J, Leonards PEG, de Boer J, Brinkman UA. Quadropole mass spectrometer operating in the electron-capture negative ion mode as detector for comprehensive two-dimensional gas chromatography. J Chromatogr A. 2005;1067:255-64.

Ma X, Chen C, Zang H, Cao Y, Wang Z, Yao Z, Chen J, Chen J. Congenerspecific distribution and bioaccumulation of short-chain chlorinated paraffins in sediments and bivalves of the Bohai Sea, China. Mar Pollut Bull. 2014;79:299-304.

Marvin CH, Painter S, Tomy GT, Stern GA, Breakevelt E, Muir DCG. Spatial and temporal trends in short-chain chlorinated paraffins in Lake Ontario sediments. Environ Sci Technol. 2003;37:4561-8.

Parera J, Santos FJ, Galceran MT. Microwave-assisted extraction versus Soxhlet extraction for the analysis of short-chain chlorinated alkanes in sediments. J Chromatography A. 2004;1046:19-26.

Randall EL. Improved method for fat and oil analysis by a new process of extraction. J AOAC. 1974;57(5):1165-98.

Reth M, Ciric A, Christensen GN, Heimstad ES, Oehme M. Short and medium chain chlorinated paraffins in biota from the European Arctic differences in homologue group patterns. Sci Total Environ. 2006;367:252-60.

Reth M, Oehme M. Limitations of low resolution mass spectrometry in the electron capture negative ionization mode for the analysis of short- and medium-chain chlorinated paraffins. Anal Bioanal Chem. 2004;378(7):1741-7. 
Reth M, Zencak Z, Oehme M. First study of congener group patterns and concentrations of short- and medium-chain chlorinated paraffins in fish from the North and Baltic Sea. Chemosphere. 2005;58(7):847-54.

Tölgyessy PS, Nagyová S, Sládkovičová M. Determination of short chain chlorinated paraffins in water by stir bar sorptive extraction-thermal desorption-gas chromatography-triple quadrupole tandem mass spectrometry. J Chromatography A. 2017;1494:77-80.

Tomy GT, Muir DCG, Stern GA, Westmore JB. Levels of $C_{10}-C_{13}$ polychloro-n-alkanes in marine mammals from the Arctic and the St. Lawrence River estuary. Environ Sci Technol. 2000;34:1615-9.

Tomy GT, Stern GA. Analysis of $\mathrm{C}_{14}-\mathrm{C}_{17}$ polychloro-n-alkanes in environmental matrixes by accelerated solvent extraction-high-resolution gas chromatography/ electron capture negative ion high-resolution mass spectrometry. Anal Chem. 1999;71:4860-5.

Tomy GT, Stern GA, Muir DCG, Fisk AT, Cymbalisty CD, Westmore JB. Quantifying $C_{10}-C_{13}$ polychloroalkanes in environmental samples by high-resolution gas chromatography/electron capture negative ion high-resolution mass spectrometry. Anal Chem. 1997;69:2762-71.

UNEP/POPS/POPRC.11/4, 2015. Persistent Organic Pollutants Review Committee, Eleventh Meeting, Draft Risk Profile: Short-chained Chlorinated Paraffins. Stockholm Convention on Persistent Organic Pollutants. Rome.

van Mourik LM, Caroline G, Leonards PEG, de Boer J. Chlorinated paraffins in the environment: a review on their production, fate, levels and trends between 2010 and 2015. Chemosphere. 2016:155:415-28.

Yuan B, Wang T, Zhu NL, Zhang KG, Zeng LX, Fu JJ, Wang YW, Jiang GB. Short chain chlorinated paraffins in mollusk from coastal waters in the Chinese Bohai Sea. Environ Sci Technol. 2012;46:6489-91.

Zencak Z, Borgen A, Reth M, Oehme M. Evaluation of four mass spectrometric methods for the gas chromatographic analysis of polychlorinated n-alkanes. J Chromatogr A. 2005;1067:295-301.

Zeng L, Chen R, Zhao Z, Wang T, Gao Y, Li A, Wang Y, Jiang G, Sun L. Spatial distribution and deposition chronology of short chain chlorinated paraffins in marine sediments across the Chinese Bohai and Yellow Seas. Environ Sci Technol. 2013;47(20):11449-56.

Zeng LX, Zhao ZS, Li HJ, Wang T, Liu Q, Xiao K, Du YG, Wang YW, Jiang GB. Distribution of short chain chlorinated paraffins in marine sediments of the East China Sea: influencing factors, transport and implications. Environ Sc Technol. 2012;46:9898-906.

\section{Submit your manuscript to a SpringerOpen ${ }^{\circ}$ journal and benefit from:}

- Convenient online submission

- Rigorous peer review

- Open access: articles freely available online

- High visibility within the field

- Retaining the copyright to your article

Submit your next manuscript at $\boldsymbol{s p r i n g e r o p e n . c o m ~}$ 